\title{
Depression Among Patients with Chronic Cluster Headaches
}

Laraib Jumani ${ }^{1}$, Reema Kumari ${ }^{2}$, Deepak Kataria ${ }^{2}$, Vinesh Kumar ${ }^{3}$, Syed Muhammad Usama ${ }^{4}$, Aakash Chandnani ${ }^{5}$, Ujala Zubair ${ }^{6}$

1. Internal Medicine, Pakistan Institute of Medical Sciences, Islamabad, PAK 2. Internal Medicine, Chandka Medical College Hospital, Larkana, PAK 3. Internal Medicine, Ghulam Mohammad Mahar Medical College, Sukkur, PAK 4. Internal Medicine, Dow University of Health Sciences, Karachi, PAK 5. Internal Medicine, Jinnah Sindh Medical University, Karachi, PAK 6. Miscellaneous, Dow University of Health Sciences, Karachi, PAK

Corresponding author: Ujala Zubair, ujalazubair86@gmail.com

\begin{abstract}
Introduction: Chronic headaches account for a significant proportion of people leading a poor quality of life. Chronic cluster headaches can be defined as episodes of headache usually around the eye in the pattern of a cluster lasting 15-180 minutes each followed by multiple similar episodes occurring at a frequency of 1-8 times per day.
\end{abstract}

Method: This cross-sectional study was conducted in Jinnah Postgraduate Medical Center, Karachi. One hundred patients who were diagnosed cases of chronic cluster headaches were asked to fill the Beck Hopelessness Scale (BHS), Headache Impact Test (HIT), and Hospital Anxiety and Depression Scale (HADS).

Results: Of our study subjects, 57 were males and 43 were females. The mean HIT-6 score among these patients was found to be $60.5 \pm 7.67(\mathrm{p}$-value $=0.04)$. The mean BHS score among these patients was found to be $13 \pm 6.87$. The mean HADS reporting anxiety (HADS-A) was found to be $12.54 \pm 5.65$; whereas, the mean HADS reporting depression (HADS-D) was found to be $7.65 \pm 4.65$.

Conclusion: Patients with chronic cluster headaches have higher scores than the general population. There is an association between headache syndromes and depression which require further investigation.

Received 10/11/2019

Review began 10/13/2019 Review ended 10/13/2019 Published 10/15/2019

๑) Copyright 2019 Jumani et al. This is an open access article distributed under the terms of the Creative Commons Attribution License CC-BY 3.0., which permits unrestricted use, distribution, and reproduction in any medium, provided the original author and source are credited.
Categories: Neurology, Psychiatry

Keywords: cluster headaches, depression, headache syndromes, quality of life

\section{Introduction}

Chronic headaches account for a large proportion of people having a poor quality of life. There are various headache syndromes; cluster headaches are among one of them. These are usually unilateral headaches and rarely bilateral. It occurs usually in the pattern of cluster. It can be broadly classified into two categories: episodic cluster headache which occurs in episodes and chronic cluster headaches which is much more debilitating [1].

The World Health Organization (WHO) has recognized chronic headache syndromes as among the ten most disabling conditions in the world [2]. Some females have described cluster headaches as being much more painful than giving birth to a child [3]. Studies have shown that chronic headaches have been associated with cognitive decline. This can be explained by the involvement of structures in chronic cluster headache which impair the thinking and decision-making capability of a person during the periods of attack [4-5].

\section{Materials And Methods}

This is a cross-sectional study conducted at the department of neurology, Jinnah Postgraduate Medical Center in Karachi, Pakistan. Patients diagnosed with chronic cluster headaches were contacted via telephone. Informed consent was taken before including them in the study. They were asked to fill a survey assessing demographic variables along with scales assessing depression, anxiety, and hopelessness. The international classification of headache disorders (ICHD-II) was used for the diagnosis of cluster headache. This classification defines chronic cluster headaches as episodes of headache usually around the eye in the pattern of a cluster lasting 15-180 minutes each followed by multiple similar episodes occurring at a frequency of 1-8 times per day [6]. Patients with co-morbid conditions such as diabetes, hypertension and any other conditions were excluded from the study. Patients with addictions such as smoking, alcoholism, and any other substance use were excluded from the study. This was done to exclude the effect of these comorbid conditions on anxiety, depression, and hopelessness among subjects. A total of 100 patients were selected. The sampling technique applied was random sampling.

Participants were asked to fill the Beck Hopelessness Scale (BHS), Headache Impact Test (HIT), and Hospital 


\section{Cureus}

Anxiety and Depression Scale (HADS). The HIT-6 is a six-item scale that is a reliable and valid tool for assessing the impact of headache on the cognitive and social well being of an individual. The score range is from 36-78. It has been proven to have good internal consistency along with good test and re-test reliability. It is easy to use for researchers and clinicians [7].

The HADS is a 14-item scale used by clinicians to assess the level of anxiety and depression among patients. Seven items from this scale are used for assessment of anxiety and seven items are used for depression. The scoring ranges from $0-21[8]$.

BHS is a 20 -item questionnaire designed to measure hopelessness. It can measure hopelessness by assessment of three components: feelings about future, loss of motivation, and expectations [9].

\section{Results}

Our study comprised of 100 patients. Of them 57 were males and 43 were females. The age range was 22-52 years. All of these patients were diagnosed with cases of chronic cluster headaches. The mean HIT-6 score among these patients was found to be $60.5 \pm 7.67$ ( $\mathrm{p}$ value $=0.04$ ). The mean BHS score among these patients was found to be $13 \pm 6.87$. Table 1 shows the mean of various components of the BHS score among our study subjects. The mean HIT-6 score among patients was found to be $60.52 \pm 9.28$. Scores greater than 50 are considered to have a significant impact of headache on the patient's well being. The mean HADS reporting anxiety (HADS-A) was found to be $12.54 \pm 5.65$; whereas, the mean HADS reporting depression (HADS-D) was found to be $7.65 \pm 4.65$.

\section{COMPONENTS OF THE BECK HOPELESSNESS SCALE}

I look forward to the future with hope and enthusiasm

I might as well give up because there is nothing I can do about making things better for myself

When things are going badly I am helped by saying they cannot stay this way forever

I cant imagine what my life would be like after ten years

I have enough time to accomplish the things I want to do

In the future I expect to succeed in what concerns me the most.

My future seems dark to me.

I happen to be particularly lucky and expect to get more things in life than the average person

I just can't get the breaks and there is no reason that I will get in the future.

My past experiences have prepared me well for the future.

All I can see ahead of me is unpleasantness rather than pleasantness.

I don't expect to get what I really want

When I look ahead at the future I expect to be happier than I am now.

Things just don't work out the way I want them to.

I have great faith in future.

I never get what I want so its foolish to want anything.

Its very unlikely that I will get any real satisfaction in the future.

The future seems vague and uncertain to me

I can look forward to more good times than bad times.

There is no point of really trying to get anything because I wont get it.

\section{MEAN STANDARD DEVIATION}

$0.7 \quad 0.67$

$0.8 \quad 0.20$

$0.87 \quad 0.564$

$0.54 \quad 0.76$

$0.65 \quad 0.34$

$0.8 \quad 0.6$

$0.34 \quad 0.65$

$0.65 \quad 0.87$

$0.35 \quad 0.78$

$0.45 \quad 0.89$

$0.54 \quad 0.45$

$0.65 \quad 0.25$

$0.56 \quad 0.59$

$0.76 \quad 0.56$

$0.43 \quad 0.57$

$0.56 \quad 0.54$

$0.9 \quad 0.52$

$0.63 \quad 0.76$

$0.78 \quad 0.43$

$0.47 \quad 0.75$

TABLE 1: Response of patients against the Beck Hopelessness Scale (BHS)

Discussion

Torkamani et al. have described differences between various aspects of routine life of healthy controls and 
those with cluster headaches either episodic or chronic. His study reports a mean HIT-6 score among patients with chronic cluster headaches to be $64.60 \pm 4.81$, mean BHS score was found to be $11.67 \pm 5.7$, mean HADS-A score was found to be $11.63 \pm 3.70$, and HADS-D score was found to be $9.75 \pm 3.54$ [10]. In contrast to the study by Torkamani et al., our study reports mean HIT-6 score of $60 \pm 7.67$, mean BHS score of $13 \pm 6.87$, mean HADS-A score of $12.54 \pm 5.65$, and mean HADS-A score of $7.65 \pm 4.65$.

Some studies have reported that cluster headaches have a much more adverse effect on the quality of life as compared to migraine headaches [11]. Symptoms of depression, anxiety, and suicidal thoughts are more common in patients with chronic headaches as compared to healthy controls [12].

Choi et al. concluded in his study that people with cluster headaches end up with more burden related to employment because of being less efficient due to debilitating cluster headaches [13]. Muneer et al. conducted a study in which he assessed the frequency of primary headache syndrome among patients with major depressive disorder. His results demonstrate that around one-third of patients with depression have any of one underlying chronic headache syndromes [14]. There can be an underlying association between chronic headache syndromes and depression and further studies are required to evaluate it. Some studies have demonstrated that tension-type headaches and migraines have a much greater association with depression than any other chronic headache syndromes [15].

An Italian based study concluded that a third of patients with chronic headache syndromes have major depression. In this study, depression was assessed using the Mini International Neuropsychiatric Instrument (MINI) in secondary and tertiary care hospitals [16].

The limitations of this study include a small sample size. In a third world country such as Pakistan, due to the limited availability of health care services, the majority of patients with cluster headaches remain undiagnosed. Our study only targets the population receiving treatment for cluster headaches. There is a chance that because of the treatment received, the level of depression, anxiety, and, hopelessness among this population will be significantly less than that of the population which remains undiagnosed.

Further studies assessing the differences in the routine life of patients with cluster headaches are required.

\section{Conclusions}

It can be concluded that there is an association between chronic headache syndromes, depression, anxiety, and hopelessness. Further investigations can strengthen the association. Multi-modal treatment involving psychologists and psychotherapists can improve the quality of life among patients with chronic cluster headaches.

\section{Additional Information \\ Disclosures}

Human subjects: Consent was obtained by all participants in this study. JINNAH POSTGRADUATE MEDICAL CENTER issued approval IRB-027-JPMC. Animal subjects: All authors have confirmed that this study did not involve animal subjects or tissue. Conflicts of interest: In compliance with the ICMJE uniform disclosure form, all authors declare the following: Payment/services info: All authors have declared that no financial support was received from any organization for the submitted work. Financial relationships: All authors have declared that they have no financial relationships at present or within the previous three years with any organizations that might have an interest in the submitted work. Other relationships: All authors have declared that there are no other relationships or activities that could appear to have influenced the submitted work.

\section{References}

1. Olesen J, Steiner TJ: The international classification of headache disorders, 2nd edn (ICDH-II). J Neurol Neurosurg Psychiatry. 2004, 75:808-811. 10.1136/jnnp.2003.031286

2. Younger DS: Epidemiology of migraine. Neurol Clin. 2016, 34:849-61. 10.1016/i.ncl.2016.06.011

3. Matharu MS, Goadsby PJ: Cluster headache: focus on emerging therapies . Expert Rev Neurother. 2004, 4:895-907. 10.1586/14737175.4.5.895

4. Eccleston C, Crombez G: Pain demands attention: a cognitive-affective model of the interruptive function of pain. Psychol. 1999, 125:356-366. 10.1037/0033-2909.125.3.356

5. Walker J: Pain and distraction in athletes and non-athletes. Percept Mot Skills. 1971, 33:1187-90. 10.2466/pms.1971.33.3f.1187

6. May A, Schwedt TJ, Magis D, Pozo-Rosich P, Evers S, Wang SJ: Cluster headache. Nat Rev Dis. 2018, 4:10.1038/nrdp.2018.6

7. Yang M, Rendas-Baum R, Varon SF, Kosinski M: Validation of the Headache Impact Test (HIT-6 ${ }^{\mathrm{TM}}$ ) across episodic and chronic migraine. Cephalalgia. 2011, 31:357-67. 10.1177\%2F0333102410379890

8. Zigmond AS, Snaith RP: The hospital anxiety and depression scale. Acta Psychiatr Scand. 1983, 67:361-70. 10.1111/j.1600-0447.1983.tb09716.x

9. Beck AT, Weissman A, Lester D, Trexler L: The measurement of pessimism: the hopelessness scale. J 


\section{Cureus}

Consult Clin Psychol. 1974, 42:861-865. 10.1037/h0037562

10. Torkamani M, Ernst L, Cheung LS, Lambru G, Matharu M, Jahanshahi M: The neuropsychology of cluster headache: cognition, mood, disability, and quality of life of patients with chronic and episodic cluster headache. J Headache Pain. 2015, 55:287-300. 10.1111/head.12486

11. Jürgens TP, Gaul C, Lindwurm A: Impairment in episodic and chronic cluster headache. Cephalalgia. 2011, 31:671-82. 10.1177\%2F0333102410391489

12. Donnet A, Lanteri-Minet M, Guegan-Massardier E: Chronic cluster headache: a French clinical descriptive study. J Neurol Neurosurg Psychiatry. 2007, 78:1354-1358. 10.1136/jnnp.2006.112037

13. Choi YJ, Kim BK, Chung PW, et al.: Impact of cluster headache on employment status and job burden: a prospective cross-sectional multicenter study. J Headache Pain. 2018, 19:78. 10.1186/s10194-018-0911-x

14. Muneer A, Farooq A, Farooq JH, Qurashi MS, Kiana IA, Farooq JS: Frequency of primary headache syndromes in patients with a major depressive disorder. Cureus. 2018, 10:e2747. 10.7759/cureus.2747

15. Goulart AC, Santos IS, Brunoni AR, et al.: Migraine headaches and mood/anxiety disorders in the ELSA Brazil. J Headache Pain. 2014, 54:1310-1319. 10.1111/head.12397

16. Beghi E, Bussone G, D’Amico D, et al.: Headache, anxiety and depressive disorders: the HADAS study . J Headache Pain. 2010, 11:141-150. 10.1007/s10194-010-0187-2 